\title{
Communications
}

\section{Synthesis of Ophiocerin C}

\author{
Dong-Min Lee, Heesoon Lee, ${ }^{\dagger}$ and Han-Young Kang ${ }^{-}$ \\ Department of Chemistrv, Chungbuk National Chiversin. Cheongiu. Chungbuk 361-763. Korea \\ E-mail: hwangiâchunghuk ac.kr \\ College of Pharmacy, Chungbuk National University. Cheongiu, Chungbuk 361-763. Korea \\ Received January 2, 2008
}

Key Words : Tetrahydropyran. Total synthesis, Carbolydrate, Ophiocerin. Natural products

Recently. Gloer group isolated several natural products from the solid-substrate fermentation cultures of fresh water fungi $O$. venezuelense. ${ }^{1}$ Investigation of the ethyl acetateextract exhibiting modest activity against Condida ablicans led to the isolation of the compounds containing the tetrahydropyran core as shown in the following (Figure 1).

Because there exist numerous biologically active natural products that have the substituted tetrahydropyrans and related structures, ${ }^{2,3}$ we decided to study the synthesis of these ophiocerins. The first and only total synthesis of ophiocerin B and C has been reported by Yadav group. ${ }^{+}$ They utilized the Sharpless asymmetric dihydroxylation as a key reaction to establish the diol stereochemistry.

We have been intrigued in ophiocerins due to the interesting array of substituents on the tetrahydropyran ring. Synthesis of these natural products would lead us to establish the routes to many natural products with substituted tetrahydropyran rings. We, therefore. decided to investigate an efficient and practical synthetic route to ophiocerin $\mathrm{C}$ starting from the easily available materials. We. herein, report an efficient carbohydrate-based approach to ophiocerin C. Retrosynthetic analysis of ophiocerin $\mathrm{C}$ is shown in Scheme 1

Ophiocerin $\mathrm{C}$ could be envisioned to be synthesized from the key intermediate 7 which, in turn. could be easily synthesized from methyl $\alpha$-D-glucopyranoside (5). Synthesis of 7 can be easily achieved by adopting the known transformations of the commercially available methyl $\alpha$-D-<smiles>CC1CC(O)C(O)CO1</smiles><smiles>CC1CC(O)C(O)CO1</smiles><smiles>CC1CC(O)C(O)CO1</smiles><smiles>C/C=C\C(=O)OC1C(C)OCC(O)C1O</smilesophiocerin A (1) ophiocerin B (2) ophiocerin C (3) ophiocerin D (4)

Figure 1. Ophiocerins.<smiles>CO[C@H]1OC(CCl)C(Cl)C(O)[C@H]1O</smiles>

6 glucopyranoside (5) (Scheme 2).

A known reaction sequence was successfully applied for the conversion of two hydroxy groups to chlorides (reaction of 5 with $\mathrm{SO}_{2} \mathrm{Cl}_{2}$ followed by the treatment with $\mathrm{NaI}$ in $\mathrm{MeOH}){ }^{5}$ Two steps proceeded easily to offer 6 in $98 \%$ yield. Decllorination was performed via a radical process $\left(\mathrm{nBul}_{3} \mathrm{SnH}\right.$, AIBN, toluene) to provide 7 in reasonable yield $(70 \%){ }^{6}$ Two hydroxy groups in diol 7 were successfully protected with benzyl groups (BnBr. NaH. DMF) in excellent yield $(98 \%)$.

Elimination of the methoxy group at the anomeric position was required for the next synthetic sequences to achieve the synthesis of ophiocerin C. Our synthetic attempt is summarized in Scheme 3.

Dibenzyl-protected compound $\mathbf{8}$ was subjected to an acidic condition in the presence of acetic andydride to achieve the conversion of the methoxy group (OMe) at the anomeric position to an acetoxy group (OAc). We realized that in addition to the conversion of the anomeric $\mathrm{OMe}$ group. one of the benzyl group was also transfomed to an acetyl group. ${ }^{7,8}$ Hydrolysis of the diacetate compound 9 offered 10 which was subjected to reduction $\left(\mathrm{NaBH}_{4}\right)$ to give 11. Selective tosylation of the primary hydroxyl group was successfully conducted ( $\left.\mathrm{TsCl}, \mathrm{Et}_{3} \mathrm{~N}\right)$. Cyclization to the tetrahydropyran ring was examined by treating with $\mathrm{NaH}$.

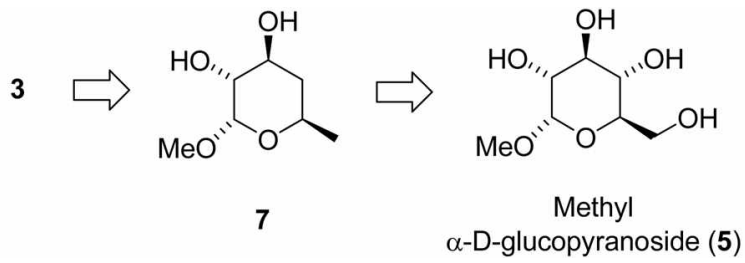

Scheme 1. Retrosynthetic analysis of ophiocerin C (3).
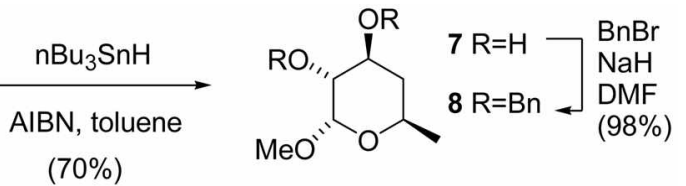

Scheme 2. Synthesis of the key intermediate 7. 


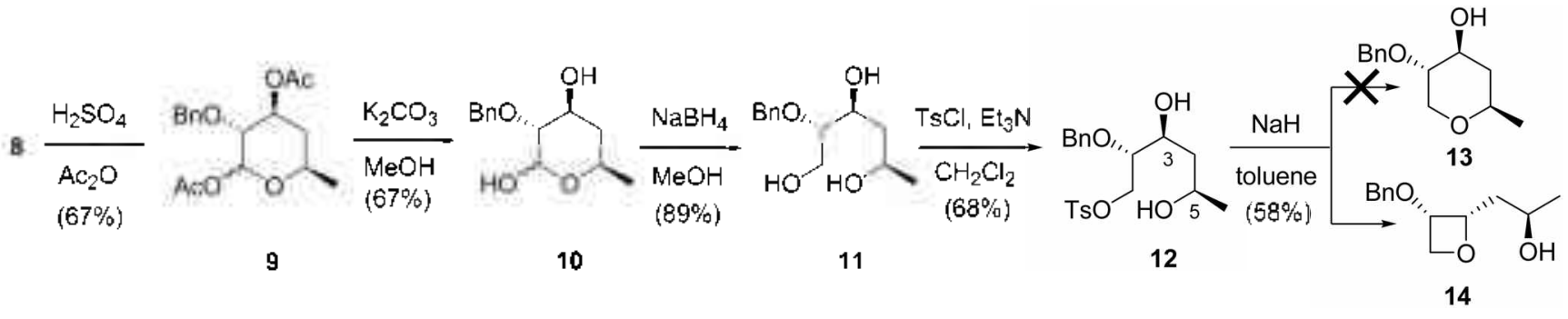

Scheme 3. Attempt to eliminate the methoxy group at the anomeric position.

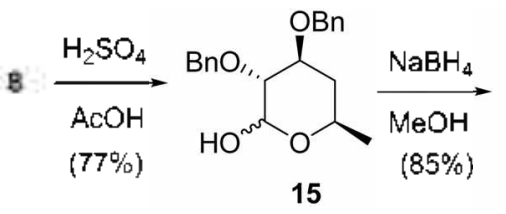

15

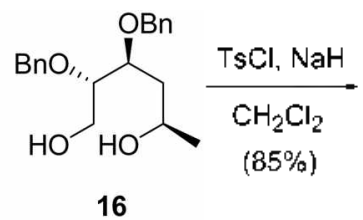

16

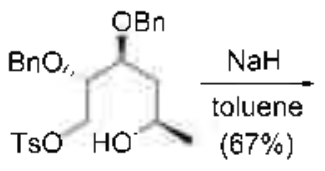

17

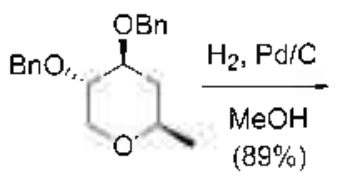

18

Scheme 4. Total synthesis of ophiocerin C.

Unfortunately. according to ${ }^{1} \mathrm{H}$ and ${ }^{13} \mathrm{C}$ NMR analyses, the product was not identified as the anticipated tetrahydropyran 13. The product was believed to be a fourmembered cyclic ether, that is. contpound $1+$ which could be formed by an attack of the oxygen atom of the C-3 hydroxy group instead of the $\mathrm{C}-5$ hydroxy group.

To circunvent the undesired cyclization we decided to adopt the reaction condition for eliminating OMe group without causing the umnecessary removal of the benzyl group. The right condition for the selective removal of methyl group eventually led to the total synthesis of ophiocerin C as summarized in Scheme 4.

We found that use of acetic acid and $3 \mathrm{M} \mathrm{H}_{2} \mathrm{SO}_{4}(2 \mathrm{eq})$ successfully eliminate the methyl group in $\mathbf{8}$ to give compound 15 (1:1 anomeric mixture). ${ }^{8.9}$ Reduction with $\mathrm{NaBH}_{+}$ generated the diol 16 which was subjected to monotosylation to produce 17. Tosylation was too slow when triethy lamine was used as a base. Stronger base $(\mathrm{NaH})$ was needed to achieve a successful selective tosylation of the primary hydroxy group. ${ }^{11}$ Thus. tetrahydropyran 18 with the correct stereochemistry at the carbons bearing hydroxy groups was prepared by cyclization with $\mathrm{NaH}$. Finally. removal of the benzyl group $\left(\mathrm{H}_{2} . \mathrm{Pd} / \mathrm{C}\right)$ completed the total synthesis of ophiocerin $\mathrm{C}$. The synthetic ophiocerin $\mathrm{C}$ showed identical spectroscopic properties with those reported in the literature.

In conclusion. we have successfully attained a total synthesis of a tertrahydropyran-containing natural product. ophiocerin $C$. The sy'nthesis was conducted in 9 steps with a total of $22 \%$ yield starting from the readily available methyl $\alpha$-D-glucopyranoside (5). This successful synthetic route could be easily expanded and applied to the synthesis of other structurally related natural products.

Acknowledgements. This work was supported by the Korea Research Foundation Grant funded by the Korean Govenmment (MOEHRD) (The Regional Research Universities Program/Chungbuk BIT Research-Oriented University Consortium).

\section{References}

1. Reategui. R. F.: Gloer. T. B.: Campbell. J.: Shearer. C. A. J. Nat. Prod 2005. 68.701-705.

2. Clarke, P. A.; Santos, S. Em: J. Org. Chem. 2006, 2045-2053.

3. For recent examples of benzopyran-containing natural products. see: (a) Lee. Y. R.: Wang. X.: Kim, Y. M.; Shim, J. J.: Kim, B. N.: Han. D. H. Bull. Korean Chem. Soc. 2007. 28, 1735-1738. (b) Lee, Y. R.; Wang. X. Bull. Korean Chem. Soc. 2007, 28. 2061-2064.

4. Yadav. J. S.; Lakshmi, P. N.; Harshavardhan. S. J.: Subba Reddy. B. V. Synlett 2007. 1945-1947.

5. Szarek, W. A.; Kong, X. In Preparative Carbohydrate Chemistry: Hannesian, S.. Ed.: Marcel Dekiker: New York. 1997; p 118.

6. Crotti, P.: Di Bussolo, V; Favero, L.: Macchia. F.: Pineschi. M. Tetrahedron 2002, 58, 6069-6091.

7. Nicolau, K. C.: Daines, R. A.: Ogawa, Y.; Charkraborty, I. K. d. Ant Chem. Soc. 1988. 110. 4896-4705.

8. Procedure tor the preparation of 9 and 15: Compound (9). Compound 8 (550 mg. $1.47 \mathrm{mmol}$ ) was suspended in $\mathrm{Ac}_{2} \mathrm{O}$ (5 $\mathrm{mL}$ ) and stirred under nitrogen at $0{ }^{\circ} \mathrm{C}$. Ac $c_{2} \mathrm{O}$ solution $(0.5 \mathrm{~mL})$ of concentrated $\mathrm{H}_{2} \mathrm{SO}_{4}$ ( 5 drops in $0.7 \mathrm{~mL}$ of $\mathrm{Ac}_{2} \mathrm{O}$ ) was added. and the cooling bath was removed. Stiring was continued until completion of the reaction $(0.5 \% 1 \mathrm{~h})$. after which the reaction was quenched with solid anthydrous $\mathrm{NaHC}_{3}(0.2 \mathrm{~g})$. 'l he misture was stirred for 10 min at $25^{\circ} \mathrm{C}$. "lhen. the mixture was diluted with ether $(80 \mathrm{~mL})$ and saturated aqueous $\mathrm{NaHC}()_{3}$ solution $(150 \mathrm{~mL})$. After the bubbling ceased. the organic phase was separated and the aqueous layer was reextracted with ether $(50 \mathrm{~mL})$. 'lhe combined ethereal solution was washed with $\mathrm{H}_{2} \mathrm{O}(25 \mathrm{~mL})$ and brine $(25 \mathrm{~mL})$, dried $\left(\mathrm{MgSO}_{4}\right)$, and concentrated. Purification by flash column chromatography (20-50\% ether in petroleum ether) provided the desired compound 9 (320 mg. $67^{\circ} .3: 1$ anomeric mixture) as a crystalline solid: $m p 75-77^{\circ} \mathrm{C}$. Compound (15). Compound 8 (3.6g. $10.5 \mathrm{mmol})$ are dissolved in acetic acid (15 $\mathrm{mL})$ and $\mathrm{H}_{2} \mathrm{SO}_{4}(3 \mathrm{M}, 7 \mathrm{~mL})$ and stirred at $85^{\circ} \mathrm{C}$ for $4.5 \mathrm{~h}$. Then cold $\mathrm{H}_{2} \mathrm{O}(20 \mathrm{~mL})$ and toluene $(20 \mathrm{~mL})$ are added. The aqueous phase is extracted with toluene $(3 \times 30 \mathrm{~mL})$. The combined organic phases are washed with saturated aqueous $\mathrm{NaCl}$ solution, dried $\left(\mathrm{MgSO}_{4}\right)$, and concentrated. Purification of the residue by flash chromatography (hexane: $\mathrm{EtOAc}=5: 1$ ) to yield the desired compound 15 (2.65 g. $77^{\circ}$. . $1: 1$ anomeric misture) as a colorless syrup.

9. Lindhorst. T. K. Essentials of Corbohndrate Chemistry and Biochentistry: Wiley-VCH: Weinheim. 2000: p 41.

10. Charkraborty. T. K.: Reddy. V. R.: Reddy. T. J. Tetrohedron 2003. $59.8613-8622$. 